\title{
Non-invasive monitoring of glucocorticoid metabolites in brown hyaena (Hyaena brunnea) faeces
}

A. Hulsman, ${ }^{1,2}$ F. Dalerum, ${ }^{3,4, *}$ A. Ganswindt, ${ }^{4,5}$ S. Muenscher, ${ }^{5}$ H.J. Bertschinger, ${ }^{5}$ M. Paris ${ }^{1,2}$

1) Institute for Breeding Rare and Endangered African Mammals, Edinburgh, United Kingdom

2) Department of Equine Sciences, Faculty of Veterinary Science, Utrecht University, Netherlands

3) Centre for Wildlife Management, University of Pretoria, Pretoria, RSA

4) Mammal Research Institute, Department of Zoology and Entomology, University of Pretoria, Pretoria, RSA

5) Department of Production Animal Studies, Faculty of Veterinary Science, University of Pretoria, Pretoria, $R S A$

*) Correspondence to: Fredrik Dalerum, Centre for Wildlife Management, Hatfield Experimental Farm, University of Pretoria, 0002 Pretoria, RSA. Phone: +27 72 2267689. Fax: +27 124206096. E-mail: fredrik.dalerum@zoology.up.ac.za

Short title: Non-invasive stress monitoring in brown hyaenas

\section{Abstract}

The brown hyaena (Hyaena brunnea) is the least known of the large predators of southern Africa. The current IUCN status of the brown hyaena is "Near Threatened", and there are conservation concerns related to a general lack of biological knowledge of the species. For instance, a better knowledge of the responses to environmental and social stressors would improve our abilities to sustainably manage brown hyaena populations in both captive and free-ranging environments. We conducted adrenocorticotrophic hormone $(\mathrm{ACTH})$ challenges in one female and one male adult brown hyaena at Lion Park Zoo, South Africa, to validate measurements of glucocorticoid metabolites (GCM) in brown hyaena faeces via an enzyme linked immunoassay (EIA). We also measured gastrointestinal transit times (GIT times) and the GCM degradation in faeces left in ambient temperature for up to 32 hours to more reliably assess the use of this assay as a tool for non-invasive glucocorticoid measurements. Intramuscular injections of synthetic ACTH yielded GCM levels of $388 \%$ (female) and $2682 \%$ (male) above baseline with peak increases occurring 25 40 hours post injection. The time delay of faecal GCM excretion approximately corresponded with food transit time in the brown hyaenas. Faecal GCM levels declined significantly over time since defecation. Our results provided a good validation that faecal GCM's accurately reflects circulating glucocorticoid stress hormones in brown hyaenas, but we highlight that samples have to be frozen immediately after defecation to avoid bias in the measurements due to bacterial degredation.

Keywords: Hyaena brunnea, faecal glucocorticoid metabolites, ACTH challenge test, GIT times, degradation rate 


\section{INTRODUCTION}

Brown hyaena's (Hyaena brunnea) are distributed throughout the south west arid zone of Africa [Skinner and Chimimba 2005]. It is the least studied of the large carnivores of southern Africa, and although the current IUCN status of the brown hyaena only is "Near Threatened" [IUCN, 2007], there are conservation concerns because at present there is a lack of knowledge on many aspects of the biology of the species [Mills and Hofer, 1998; Wiesel et al., 2008]. For instance, a better knowledge of the physiological responses to environmental and social stressors would improve our abilities to sustainably manage brown hyaenas both in captive and free-ranging environments.

Stress can be defined as the physiological response elicited when an individual perceives a threat to its homeostasis. One of the responses to physiological or behavioural stressors is the increased secretion of glucocorticoids by the hypothalamic-pituitary-adrenal axis. Although GC responses are adaptive in the short term, chronically elevated GC levels can produce an array of pathologies, including reproductive suppression, ulcers, muscle wasting and immune suppression [Munck, 1984; Sapolsky, 1992; Dobson and Smith, 2000]. Monitoring GC levels is therefore of central importance in a number of disciplines of biological research and animal management.

Non-invasive monitoring of hormone levels has several advantages compared to more traditional techniques based on blood samples. For instance, there is no need to capture the animal and thereby disturbing the subject, and faecal hormone metabolites represent a pool of metabolites rather than reflecting the short term fluctuations that circulating blood undergoes [Bronson, 1989; Creel et al., 1996]. However, non-invasive measurements need to be validated to ensure that the measured compounds reflect circulating levels of the biologically active target agents [Cekan, 1975; Schwarzenberger et al., 1996]. Moreover, knowing the degradation of hormone metabolites in faeces is important for accurate planning of field data collection, and for accurate interpretation of results.

The aim of this study was to validate a protocol for non-invasive monitoring of glucocorticoid metabolites (GCM) in brown hyaenas faeces. We also measured gastro-intestinal transit times (GIT) as well as the degradation rate of GCM's in faecal samples [e.g., Keay et al., 2006] to further evaluate the utility of using monitoring of feacal GCM's as a non-invasive tool to measure stress in this species.

\section{METHODS}

\section{Study animals and sample procedures}

We conducted the study on one female and one male brown hyaena at the Lion Park Zoo in Johannesburg, Gauteng, South Africa. Both animals were 6 years old at the time of the study. Each hyena was housed in a separate outdoor enclosure of approximately 10 ha each. The hyaenas were fed once a day with a diet consisting of horse and cow meat, bones, and offal. We entered the enclosures between 8 and 9 am and if possible again between 4 and 5 pm to collect faecal samples. For logistical reasons, we could not enter the enclosure more frequently. Samples were stored in glass vials at $-20^{\circ} \mathrm{C}$ until extracted. The study was conducted in accordance with the University of Pretoria Animal Care and Ethics Committee.

\section{Experimental designs}

We tested the biological validity of the protocol by injecting 50 IU of synthetic adrenocorticotrophic hormone (ACTH) (Synacthen depot, Novartis, Australia) intramuscularly in each study animal using a $\mathrm{CO}_{2}$ powered dart gun (Dan-Inject, Sellerup Skovve, Denmark). We collected faeces during a 4 day pre-injection period to provide a measure of baseline glucocorticoid levels, conducted the ACTH challenge on the fourth day of collection and collected faeces longitudinally for 4 days post-injection. 
To measure GIT times, we fed each animal a piece of meat that had been cut open and filled with plastic red party glitter as a marker. Each animal was fed the marked meat immediately after both injections had been completed. We watched the animals until they had finished eating, to be sure of the feeding time.

For the purpose of determining the rate of GCM degradation, we collected two fresh faecal droppings from each of the two study animals. We removed the faeces from the enclosures and placed them outside on the grass. We homogenized each fecal sample and separated and froze equal parts at approximately $0,0.5,1,2,4,8,16$ and 32 hours post defecation. Ambient temperatures varied from $25^{\circ} \mathrm{C}$ during the day to $15^{\circ} \mathrm{C}$ during the night. There was no rainfall. All samples for the degradation experiment were initially collected on different days.

\section{Extraction and assay}

Faecal samples were lyophilised, pulverised and sifted using a mesh strainer to remove fibrous material [Fiess et al., 1999]. Between 330-340 mg of the faecal powder was then extracted with $3 \mathrm{ml} \mathrm{90 \%} \mathrm{methanol} \mathrm{in} \mathrm{water} \mathrm{according} \mathrm{to} \mathrm{the} \mathrm{method} \mathrm{described} \mathrm{by} \mathrm{Ganswindt} \mathrm{et} \mathrm{al.} \mathrm{[2005].} \mathrm{In}$ brief, after vortexing for $15 \mathrm{~min}$ the mixture was centrifuged for $10 \mathrm{~min}$ at $3300 \mathrm{x} \mathrm{g}$. The supernatant was transferred to a micro-centrifuge tube for hormone analysis.

Immunoreactive GCM in diluted extracts were analysed with an 11-oxoaetiocholanolone enzyme immunoassay (EIA) first described by Möstl et al. [2002]. This EIA detects GCM with a $3 \alpha$-hydroxy-11-oxo structure and has successfully been validated for monitoring adrenocortical activity in various primate species, the African elephant, and other mammals [Möstl et al., 2002; Ganswindt et al., 2003; Heistermann et al., 2006]. Cross-reactivities for the 5ß-androstane-3 $\alpha$-ol-11one-17-CMO antibody (100\%) used were $37 \%$ for $5 \beta$-pregnane-3 $\alpha$-ol-11,20-dione, $3.3 \%$ for $5 \beta$ androstane-3 $\alpha, 11 \beta$-diol-17-one, $1.2 \%$ for $5 \beta$-androstane-3,11,17-trione and $<1 \%$ for 11 ketoandrosterone, etiocholanolone, pregnanediol, tetrahydrocortisol, 5ß-dihydrocortisol, cortol, 5ßpregnane-3 $\alpha, 11 \beta, 17 \alpha, 20 \alpha, 21$-pentol, 5ß-pregnane-3ß-ol-11,20-dione and 5ß-pregnane-3 $\alpha, 11 \beta$-diol20-one [Möstl et al., 2002; Huber et al., 2003]. Serial dilutions of faecal extracts (400-50000-fold) gave displacement curves which were parallel to the standard curve of the assay. Sensitivity of the assay as determined at $90 \%$ binding was $3 \mathrm{pg} / \mathrm{well}$. Intra- and interassay coefficients of variation, determined by repeated measurements of high and low concentration quality controls ranged between $4.2 \%$ and $17.3 \%$. The assay was performed on microtiter plates with a double antibody technique according to the methods described by Palme and Möstl [1997] and Ganswindt et al. [2002]. Samples from the ACTH challenge were assayed in 500-fold up to 20000-fold dilutions. Sample concentrations are expressed as $\mu \mathrm{g} / \mathrm{g}$ dry weight of fecal matter (DW).

\section{Data analysis}

We used a linear two-sample rank test using a permutation framework (implemented in the $\mathrm{R}$ package Coin, Hothorn et al. 2008) to evaluate the effect of the ACTH injection on GCM levels. We simultaneously tested the effect of ACTH injection on both study animals by blocking the independent variable over our respective study animals. We used a mixed linear model to test the effect of time on measured GCM levels (Pinheiro and Bates 2000). In the model, we used hours since defecation as a fixed continuous predictor and added each faecal sample nested within each individual as a random factor to control for interdependence both within samples and within individuals. All statistical analyses were conducted using the statistical software environment $\mathrm{R}$ version 2.10.1 for Linux (http://www.r-project.org).

\section{RESULTS}

The ACTH injection yielded significant peak GCM levels of $388 \%$ (female: $21.13 \mu \mathrm{g} / \mathrm{g}$ DW) and 2682\% (male: $63.15 \mu \mathrm{g} / \mathrm{g})$ compared to pre-injection baseline $(\mathrm{z}=3.20, \mathrm{p}=0.001$, Fig. 1$)$. Mean 
pre-injection levels were $5.44 \mu \mathrm{g} / \mathrm{g} \mathrm{DW}( \pm 1 \mathrm{sd} 2.88$, range $2.98-9.61)$ and $2.36 \mu \mathrm{g} / \mathrm{g} \mathrm{DW}( \pm 1 \mathrm{sd}$ 2.60 , range $0.05-6.78$ ) respectively for the female and male individual. Peak GCM level for the female was measured in a fresh scat approximately 25 hours after injection whereas peak glucocorticoid level for the male was measured more than 24 hours but less than 39 hours after injection. For both animals, GCM levels declined within 25 hours after the measured peak (Fig. 1). GIT transit times were approximately 15 hours for the female and 23 hours for the male. Faecal GCM's degraded significantly over time $\left(\beta=-8.2 \times 10^{-2}, \mathrm{t}=2.29, \mathrm{p}=0.032\right.$, Fig. $\left.2 \mathrm{a}\right)$, and with the exception of three sub-samples from one of the faeces (the male, sample 2, 2-4 sub-sample) the proportional rate of degradation appeared to be relatively consistent across a wide range of initial hormone concentrations (Fig. 2b).

\section{DISCUSSION}

The elevated GCM levels as a response to the ACTH challenge suggests that the measured metabolites are relevant indicators of adrenal activity. However, the intensity of the physiologically induced stress response differed between the two animals. The higher GCM peak in the male could either have been caused by individual variation in a physiological response to ACTH stimulation, or by additional stress that this animal experienced prior to the injection, since the animal refused to come out of its burrow for several hours. In spotted hyaenas, faecal glucocorticoid metabolites peaked $26 \pm 5$ hours after ACTH injection [Goymann et al. 1999]. This is similar to our results on brown hyaenas, where faecal GCM's peaked approximately 25 hours after ACTH injection in the female and between $24-39$ hours in the male.

The time delay of faecal GCM excretion approximately corresponded with food transit time in the brown hyaenas. This is in accordance with several non-carnivore species, such as sheep, ponies, and pigs [Palme et al., 1998], as well as spotted hyaenas, where GIT transit time was approximately 24 hours and faecal glucocorticoid excretion increased within 24-50 h after ACTH injection [Goymann et al., 1999].

We found a significant decline in GCM levels over time since defecation. In brown hyaenas, fresh samples should give reliable reflections of GCM levels in the collected faeces. In samples older than 5-6 hours, however, a low measured GCM level may not necessarily reflect a low initial level in that particular sample. If an old sample yields high GCM levels, it can be concluded that the initial levels of that samples probably were even higher. This highlights the need to collect fresh samples and freeze these immediately for accurate detection of faecal GCM levels in brown hyaenas. This contradicts previous data on spotted hyaenas, where faecal androgen concentrations was unaffected by delays up to $48 \mathrm{~h}$ between depositing and freezing [Dloniak et al., 2004], and baboons (Papio ursinus), where faecal GCM degradation was less than 10\% over 30 days of storage at ambient temperature [Beehner et al., 2004].

\section{CONCLUSIONS}

1. Our results provide good evidence that the EIA system used in this study accurately detects stress-related changes in circulating glucocorticoid levels in both male and female brown hyaenas. It can therefore be useful as a non-invasive tool for measuring a physiological stress response noninvasively in this species.

2. GCM time lags appear to be approximately related to GIT transit times in brown hyaenas, as in many other species.

3. Our results highlight the need to collect fresh samples and freeze these immediately for accurate determination of GCM levels to avoid confounding effects caused by bacterial degradation. 


\section{ACKNOWLEDGEMENTS}

We thank everyone at the Lion Park Zoo in Johannesburg for allowing us to perform the research and for logistical help during the trials. Financial support was provided by Utrecht University, The National Graphic Society/Wait's foundation, the National Research Foundation of South Africa and the University of Pretoria research fellowship program. John Hanks and Bob Millar from IBREAM (Institute for Breeding Rare and Endangered Mammals) facilitated logistic support for the study, and Daniel Swanepoel kindly provided assistance during the ACTH injections.

\section{REFERENCES}

Beehner JC, Whitten PL. 2004. Modifications of a field method for fecal steroid analysis in baboons. Physiology \& Behavior 82:269-277.

Bronson FH. 1989. Mammalian reproductive biology. Chicago: Univ. Chicago Press.

Cekan Z. 1975. Assessment of reliability of steroid radioimmunoassays. J Steroid Biochem 6:271175.

Creel S, Creel NM, Monfort SL. 1996. Social stress and dominance. Nature 379:212.

Dobson H, Smith RF. 2000. What is stress, and how does it affect reproduction? Anim Reprod Sci 60-61:743-752.

Dloniak SM, French JA, Place NJ, Weldele ML, Glickman SE, Holekamp KE. 2004. Non-invasive monitoring of fecal androgens in spotted hyaenas (Crocuta crocuta) Gen Comp Endocrinol 135:51-61.

Fiess M, Heistermann M, Hodges JK. 1999. Patterns of urinary and fecal steroid excretion during the ovarian cycle and pregnancy in the African elephant (Loxodonta africana). Gen Comp Endocrinol 115:76-89.

Ganswindt A, Heistermann M, Borragan S, Hodges JK. 2002. Assessment of testicular endocrine function in captive African elephants by measurement of urinary and fecal androgens. Zoo Biol 21:27-36.

Ganswindt A, Palme R, Heistermann M, Borragan S, Hodges JK. 2003. Non-invasive assessment of adrenocortical function in the male African elephant (Loxodonta africana) and its relation to musth Gen Comp Endocrinol 134:156-166.

Ganswindt A, Heistermann M, Hodges JK 2005. Physical, physiological and behavioural correlates of musth in captive African elephants (Loxodonta africana). Physiol Biochem Zool 78:505514.

Goymann W, Möstl E, Vanthof T, East ML, Hofer H. 1999. Noninvasive fecal monitoring of glucocorticoids in spotted hyaenas, Crocuta crocuta. Gen Comp Endocrinol 114:340-348.

Heistermann M, Palme R, Ganswindt A, 2006 Comparison of different enzymeimmunoassays for assessment of adrenocortical activity in primates based on fecal analysis IN: American J Primatol 68:257-273.

Hothorn T, Kornik K, van de Wiel MA, Zeileis W, 2008. Implementing a class of permutation tests: the Coin package. J Statist Softw 28:1-23.

Huber S, Palme R, Arnold W, 2003. Effects of season, sex, and sample collection on concentrations of fecal cortisol metabolites in red deer (Cervus elaphus). Gen Comp Endocrinol 130: 48-54.

IUCN. 2007. IUCN red list of threatened species. http://www.iucn.org.

Keay JM, Singh J, Gaunt MC, Kaur T. 2006. Fecal glucocorticoids and their metabolites as indicators of stress in various mammalian species. J Zoo Wildl Med 37:234-244

Mills G, Hofer H. editors 1998. Hyaenas status survey and conservation action plan. Gland: IUCN.

Möstl E, Maggs JL, Schrötter G, Besenfelder U, Palme R 2002. Measurement of cortisol metabolites in faeces of ruminants. Vet Res Commun 26:127-39.

Munck A, Guyre PM, Holbrook NJ. 1984. Physiological functions of glucocorticoids in stress and their relation to pharmalogical actions. Endocr Rev 5:25-44. 
Palme R, Möstl E. 1997. Measurement of cortisol metabolites in faeces of sheep as a parameter of cortisol concentrations in blood. Int J Mamm Biol 62:192-197.

Palme R, Bobia C, Messman S, Möstl E. 1998. Measuring faecal cortisol metabolites: a noninvasive tool to evaluate adrenocortical activity in mammals. Adv Ethol 33:27-46.

Pinheiro JC, Bates DM, 2000. Mixed-effects models in S and S-plus.Berlin: Springer Verlaag.

Sapolsky R. 1992. Neuroendocrinology of the stress response. In: Becker JB, Breedlove SM, Crews D. editors. Behavioral endocrinology. Cambridge, Massachusetts: MIT Press. p 287-324.

Schwarzenberger, F, Möstl E, Palme R, Bamberg E. 1996. Faecal steroid analysis for non-invasive monitoring of reproductive status in farm, wild and zoo animals. Anim Reprod Sci 42:515526.

Skinner JD, Chimimba CT. 2005 Mammals of the Southern African Subregion. Cambridge: Cambridge University Press.

Wiesel I., Maude G.., Scott D., Mills G.. 2008. Hyaena brunnea. In: IUCN 2010. IUCN Red List of Threatened Species. Version 2010.1. www.iucnredlist.org. 

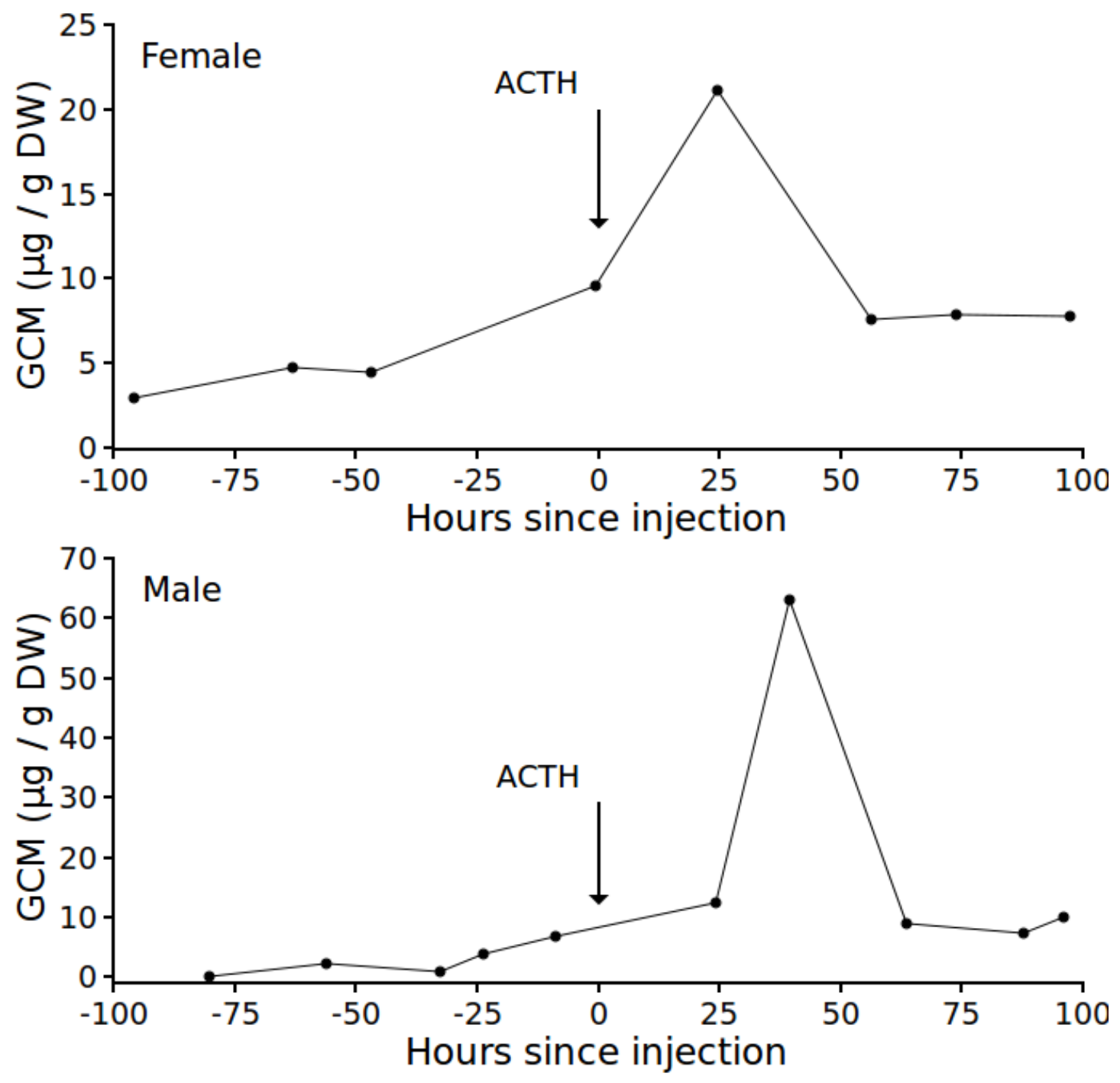

Fig 1. Responses of immunoreactive GCM concentrations in faeces following IM injections of synthetic ACTH in one female and one male captive brown hyaena. Note different scales on the yaxes for the two animals. 

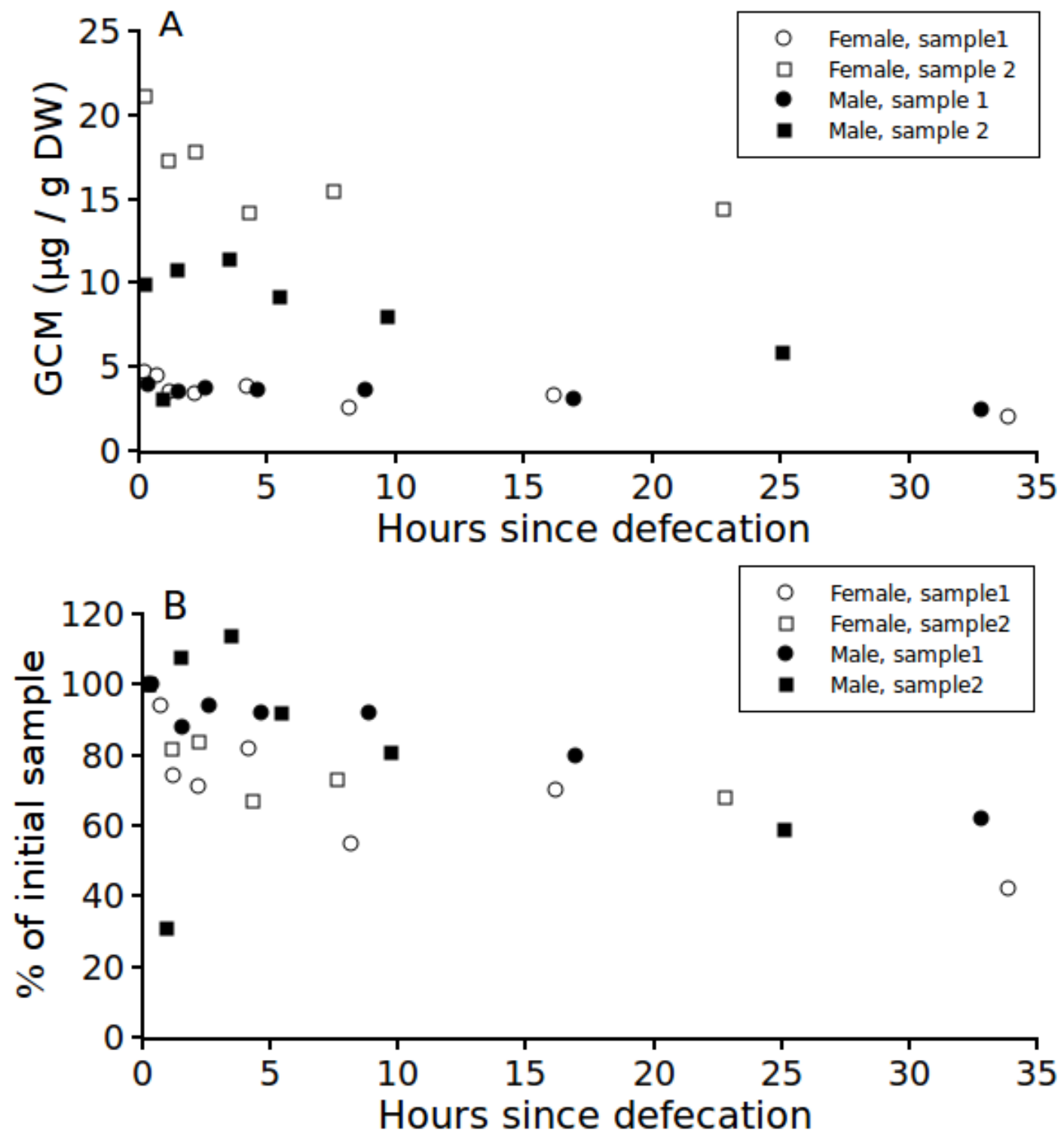

Fig 2. Net (A) and relative (B) degradation of GCM's in four brown hyaena faecal samples from one female and one male over time since defecation. 